\title{
Nursing News
}

What makes a nurse a nurse? In response to worldwide demand for direction on professional nursing competencies, the International Council of Nurses (ICN) has published the first such guidelines. The ICN Framework of Competencies for the Generalist Nurse is sufficiently broad to apply internationally, yet specific enough to provide guidance to countries developing their own competencies.

Today's global market includes the free movement of professionals between countries and regions. As a result, there is growing interest in common standards and competencies of nurses. ICN intends that these competencies will help clarify the role of nurses and guide future mutual recognition agreements and multicountry licensure programs. ICN expects, and considers it most important, that the competencies will require discussion and interpretation in-country, to ensure that they are sufficiently comprehensive for the national context.

Countries may wish to build upon the ICN framework, while developing additional competencies that reflect the current country-specific requirements of the nursing workforce. The publication presents a framework of competencies for the generalist nurse at the point of entry to practice, i.e., following successful completion by a student nurse of her/his country's initial nurse education program. The competencies were derived following a comprehensive review of literature from many countries and a series of consultations. The framework has been well received by nurses who have reviewed it. To ensure that the competencies remain relevant over time in the rapidly changing healthcare environment, ICN will ensure that they are reviewed regularly, updated as required and reissued as continuing guidance to countries. www.icn.ch
In other news from ICN, an American nurse who has assisted some of the world's most desperate populations is the recipient of the 2003 International Achievement Award bestowed by ICN's Florence Nightingale International Foundation (FNIF). Carol Etherington RN of Nashville, Tennessee, has designed and implemented community-based program for people living in the aftermath of war and natural disaster, working with Ministries of Health and national staffs in Bosnia, Poland, Honduras, Tajikistan, Kosovo, Sierra Leone and Angola. In her own country, Etherington has received two distinguished awards from the American Red Cross for her work as a volunteer in U.S. disasters.

The Honourable Anne McLellan, Federal Minister of Health, has announced a new \$1.5-billion Diagnostic and Medical Equipment Fund. The announcement is part of the Healthcare Action Plan agreed to by Canada's First Ministers in February 2003. The fund's principal objective is to enable provincial and territorial governments to acquire and install diagnostic and medical equipment and to train specialized staff, in order to improve access to timely, publicly funded diagnostic services.

Canada is among the highest-spending countries in terms of total healthcare spending, but ranks among the bottom third of OECD countries in the availability of healthcare technology. www.hc-sc.gc.ca

Health Canada is contributing up to $\$ 436,177$ to the WestNet Tele-Ophthalmology Project managed by the Government of the Northwest Territories. The WestNet Tele-Ophthalmology project was created to help screen Northwest Territories people with diabetes for early signs of the retinal deterioration that can lead to blindness. Trained eye technicians from the Eye Centre of the Stanton Territorial Health Authority in Yellowknife are using portable stereoscopic digital imaging equipment to create retinal images that will be forwarded to specialists at the Royal Alexandra Hospital in Edmonton for analysis and treatment recommendations. www.hc-sc.gc.ca

Expenditure on prescribed drugs continues to increase, occupying a larger proportion of total drug spending in Canada, according to a new report, Drugs Expenditure in Canada, 1985-2002, released by the Canadian Institute for Health Information. Prescribed drug spending is forecast to have reached $\$ 14.6$ billion in 2002, representing $80.3 \%$ of total drug expenditure. This corresponds to an increase of 10 percentage points since 1990 , where prescribed drugs occupied $70.3 \%$ of total drug expenditure. www.cihi.ca 
The Government of Canada is investing close to $\$ 6.5$ million in initiatives designed to ensure that Prince Edward Island residents have access to high-quality, affordable and sustainable primary healthcare services. The province will use a portion of this funding to:

- establish family health centres which include a collaborative practice of multidisciplinary health provider teams;

- develop and implement a strategy for healthy living and an improved drug utilization strategy;

- expand an integrated palliative care strategy; and

- implement videoconferencing for clinical care, and patient and provider education.

\section{www.hc-sc.gc.ca}

\section{Healthcare in Alberta is receiving an increase of} almost a half-billion dollars to ensure access to services and to implement reforms that build a better public healthcare system. Total funding for healthcare is up $\$ 492$ million, a $7.2 \%$ increase that brings the Alberta Health and Wellness budget to $\$ 7.35$ billion in 2003-04.

Continuing to ensure access to health services accounts for most of the increase in health funding. Half of the Ministry's total increase, \$245 million, goes directly to Alberta's nine health regions and two provincial boards, mostly as increases in base funding to provide services, and to buy new medical equipment. The Alberta Cancer Board's additional \$18 million includes $\$ 11$ million for cancer drugs.

The Alberta Mental Health Board receives an added $\$ 1.5$ million for the four provincial services and programs it retains: forensic psychiatry, suicide prevention, aboriginal, mental health and tele-mental health. All other mental health services are transferred to the nine health regions within the 2003-04 funding levels. In all, health authority base funding is $\$ 4.1$ billion in 2003-04.
Low-income B.C. families will pay less for eligible prescription drugs under the province's new Fair PharmaCare program, which affects about 280,000 families and seniors who face high prescription drug costs. Fair PharmaCare, which takes effect May 1, combines the existing major PharmaCare plans - the universal plan and the seniors' plan into one new program, with access based on families' ability to pay. The lower a family's income, the more financial assistance government will provide. With these changes, British Columbia will provide the second-most- generous prescription drug coverage in the country. www.gov.bc.ca

British Columbia will increase health spending this year by $\$ 319.4$ million. The combined budget for the Ministries of Health Services and Health Planning will increase from $\$ 10.2$ billion to $\$ 10.5$ billion. The revised budget of $\$ 10,528.9$ million includes $\$ 10,504.7$ million for the Ministry of Health Services and $\$ 24.2$ million for the Ministry of Health Planning.

With the latest increase, total provincial health spending across government is now $\$ 10.7$ billion, up from $\$ 9.3$ billion in Budget 2001 - an increase of $\$ 1.4$ billion over two years. Health function expenditures now account for 42.3 percent of all government spending. www.gov.bc.ca

The government of New Brunswick will invest about $\$ 120$ million more in healthcare than last year. This comprises an additional \$58.4 million set out in the 2003-04 budget estimates which were tabled recently, plus an additional $\$ 60$ million in new federal funding flowing from the First Ministers arrangement on healthcare renewal agreed to in February. www.gnb.ca

The government of British Columbia is launching a new program of nurse practitioners to improve health services by expanding the range of health professionals to care for patients. The program will begin with the addition of a total of 30 new spaces for nurse practitioners at the University of B.C. and University of Victoria in September. The spaces are part of the 547 new nursing education spaces added this year. The Health Professions Amendment Act tabled in the legislature today allows for the regulation of nurse practitioners by the Registered Nurses Association of B.C. The next step in implementing the new program will be defining the scope of practice in regulations. 
Residents of Prince Edward Island now have improved access to radiology services in their home communities, following the province-wide implementation of the new picture archiving and communications system (PACS). The cornerstone project of the Health Infostructure Atlantic Project, signed in January 2000 by the four Atlantic provinces, is known as Tele-i4 or interprovincial integration of images and information. The Tele-i4 project is the largest interprovincial implementation of PACS equipment in Canada and is accessible from every hospital in the province. Using state-of-the-art computer imaging technologies from Agfa Canada in all seven Prince Edward Island hospital diagnostic imaging departments, networks have been created to ensure that patient information and images can be electronically transferred from one location to another for referral, diagnosis and consultation.
Ontario patients in need of the latest diagnostics will soon have reduced wait times and faster access to five new magnetic resonance imaging (MRI) machines and five new computerized tomography (CT) scanners. The government will invest up to $\$ 4.6$ million annually to provide expanded diagnostic services in independent health facilities. Private sector companies will provide medically necessary insured MRI and CT scans, operating through the existing Independent Health Facilities Act, within Ontario's universally accessible, publicly funded healthcare system. A physician referral will be required for MRI and CT scans. The facilities were selected through a request for proposal process that was issued last November. The new MRIs and CT scanners will be providing expanded services this spring at $36 \%$ less than the cost of providing the same services in hospital. www.gov.on.ca/health

Saskatchewan is boosting healthcare spending by $8 \%$ to a record $\$ 2.5$ billion. A total of $\$ 61$ million has been allocated for building and renovating healthcare facilities over the next two years. In the coming year, \$19 million will be spent on health equipment, including diagnostic equipment such as new CT scanners in Yorkton and Moose Jaw and the permanent location of a CT scanner in Swift Current. Other capital equipment spending will include targeted funding for improved surgical access. Saskatchewan's health investment highlights include:

- A 6\% increase for Regional Health Authority operations and an $8.7 \%$ increase for the Saskatchewan Cancer Agency;

- $\$ 74$ million to support collective agreements that will help maintain existing health professionals and encourage others to train in these professions;

- Establishing satellite renal dialysis clinics in North Battleford and in a location in southern Saskatchewan, to be determined in the weeks ahead;

- Implementing the 24-hour telephone health advice line province-wide;

- Training 80 emergency medical personnel to EMT levels, with a three-year target of 240;

- Providing funding for 300 first-year students at the College of Nursing, including 40 in the new northern nurse training program, and 60 first-year students at the College of Medicine;

- \$4 million for return-service training bursaries to support health provider retention and recruitment; and

- Providing \$1.2 million to municipalities on a 50-50 cost-shared basis for West Nile mosquito control programs.

www.health.gov.sk.ca

The new survey, commissioned by Cancer Care Nova Scotia in February 2003, showed that $70 \%$ of the Nova Scotians polled were satisfied with their ability to access quality cancer care in their communities. In November 2000, Nova Scotians' satisfaction about access to services was rated at $61 \%$. The February survey also showed that satisfaction with the quality of cancer care grew to $68 \%$ from $62 \%$; early detection and diagnosis grew to $65 \%$ from $59 \%$; and access to medical specialists grew to $59 \%$ from $53 \%$. www.gov.ns.ca/health
A three-year progress report on the Manitoba Nursing Strategy and new initiatives to improve working conditions and respect for nurses was recently released. The three-year progress report summarizes actions taken in support of the Manitoba Nursing Strategy and provides a snapshot of the impact these actions are having on healthcare in Manitoba. The progress report is available at the new Manitoba Nursing Strategy website (www.gov.mb.ca/health/nurses/strategy.html), which also offers easy access to nursing information and resources for Manitoba nurses and patients. www.gov.mb.ca 
More nurses are being recruited, retained and trained in Nova Scotia through the province's nursing strategy and Your Health Matters plan. In releasing the second annual strategy update, Health Minister Jane Purves credited the Provincial Nursing Network and nurses themselves for the strategy's success. Government is providing almost $\$ 60$ million between 2001 and 2006 to support nursing and the nursing strategy.

In Nova Scotia, a plan focused on health promotion, more doctors and nurses, shorter wait lists, seniors' care and health services within communities was recently released by the provincial government. The government is taking immediate steps so patients get critical tests and treatments more quickly. In 2003-04, \$5 million will be invested to shorten wait lists for cardiac tests and surgeries. As well, \$45 million will be invested over the next three years to purchase diagnostic, surgical and other medical equipment. www.gov.ns.ca/health

Patients in rural communities in British Columbia will get better access to medical care through a $\mathbf{\$ 5 8 . 5 -}$ million package of benefits and financial incentives designed to attract doctors to these areas. The rural subsidiary agreement is part of last year's \$392-million working agreement between the government and the B.C. Medical Association. It is managed through the joint standing committee on rural issues, which is co-chaired by the BCMA and the Ministry of Health Services. Bonus incentives provided by the rural program are in addition to increases from the working agreement and include:

- Recruitment bonuses of up to $\$ 10,000$

- Retention premiums

- Rural continuing education benefits

- A general practitioner locum program

The province is also announcing the establishment of a rural specialist locum program that will be provincially coordinated to help health authorities ensure continuous coverage while specialists are recruited. www.gov.bc.ca

Erratum: In the last issue of Nursing Leadership (Vol. 16 No. 1) M. Judith Lyman, PhD (C), Associate Professor, UBC School of Nursing, Vancouver; Vicki Smye, $\mathrm{PhD}(\mathrm{C})$, Graduate Research Assistant, UBC School of Nursing, Vancouver and Pat Semeniuk, MSN, Clinical CoInvestigator \& Administrator, Vancouver General Hospital, were misidentified. Our apologies for the error.
The new Indigenous Peoples' Health Research Centre (IPHRC) received a funding boost of $\$ 2.725$ million over six years. The funding will support research projects in key areas of aboriginal health, including chronic diseases, indigenous healing, health delivery, disease prevention and environmental health. It will also increase opportunities for people of aboriginal ancestry to pursue health-related research and training. The centre is led by the Saskatchewan Indian Federated College (SIFC), in partnership with the University of Regina and the University of Saskatchewan. The province is providing $\$ 225,000$ in the current fiscal year, followed by annual payments of $\$ 500,000$ from 2003-04 to 2007-08.

\section{www.health.gov.sk.ca}

\section{Ontario's Premier announced that the government} will provide free tuition for nursing students who agree to begin their careers in underserviced communities.

Newfoundland is in the process of public consultations for the development of a provincial health charter. To facilitate the public review process, the government previously released a discussion paper, "Building a Healthier Future." This document contains a proposed health charter which outlines both governments' responsibility for the health and community services system and the general public's role in its own health and wise use of the health system. To obtain a copy of "Building a Healthier Future," please contact the Department of Health and Community Services at toll-free 1-866-248-9662, fax: 709-729-6737, e-mail: strategichealthplan@gov.nf.ca or through the department's website at

\section{www.gov.nf.ca/health.}

The province of Newfoundland and Labrador also recently announced it will spend \$26 million for medical and diagnostic equipment. The majority of this funding will be dispersed to regional health boards to purchase equipment such as X-ray units, ultrasound units and nuclear medicine equipment among other needs. Other allocations include funding for a second MRI unit for the province and \$5 million for picture archiving and communications system (PACS) implementation. In addition, $\$ 1$ million is being allocated to equip ambulances with defibrillators and other patient care equipment.

Send us your nursing news to publisher @longwoods.com 
The Ontario Government announced that Michael Decter has been appointed to lead a Health Capital Planning Review that will make recommendations to improve Ontario's health capital planning and approval process.

The Health Capital Planning Review will make recommendations on:

- streamlining the government's health capital planning processes;

- measuring outcomes of health capital investments based on the performance of project development and the planning and approval process;

- clarifying and strengthening accountability lines (among healthcare providers, the Ministry of Health and Long-Term Care (MOHLTC) and central agencies;

- ensuring responsibilities of all stakeholders involved in the government's health capital planning processes (MOHLTC central agencies, healthcare providers) are properly aligned; and

- ensuring the capital needs of all health services are considered in the planning process.

Panel members are Peter Janson, past Chairman and Chief Executive Officer of AMEC Inc.; Robert Schultz, Chairman of Rockwater Capital Corporation; Graham Scott, former Deputy Minister of Health and currently managing partner of McMillan Binch; Michael Strofolino, President of 50EXCEL and former President and Chief Executive Officer of the Hospital for Sick Children.

The report is expected in the fall of 2003.

Agfa Inc. recently announced that Fraser Health Authority, one of the largest health authorities in Canada, has selected Agfa HealthCare's computed radiology (CR) solutions to acquire, identify and digitize diagnostic images. The $\$ 3.59$ million agreement will see the Agfa Diagnostic Center (ADCM) CR solutions deployed across 11 of the sites administered by Fraser Health. The award currently includes 11 ADC Compact Plus ${ }^{\mathrm{TM}}$ and 16 ADC Solo ${ }^{\mathrm{TM}}$ digitizers, 14 ADC Quality System servers with the newly released ADC QS ${ }^{\text {TM }} 2.1$ software, supported with fully functional systems for patient ID and related ADC software.
As many as 240 more nurses will be educated in Nova Scotia over the next four years, under a new $\$ 7$-million training plan. Some of the training will be delivered through shorter, concentrated programs so nurses are able to care for patients in hospitals and nursing homes even sooner. Sixty additional nurses will be trained in each of the four years of the plan:

- 25 will be educated in a joint nursing program between the University College of Cape Breton and St. Francis Xavier School of Nursing;

- 25 science undergraduates will be able to take a shorter, concentrated program that prepares them for nursing in 20 months, compared to four years; and

- 10 licensed practical nurses will be able to enter a new program to become registered nurses in three years instead of four.

www.gov.ns.ca/health

\section{Industry News}

\section{Per-Se looking strong}

Per-Se Technologies (business management outsourcing services, financial and clinical software solutions and Internet-enabled connectivity) announced that it used cash on hand to reduce debt levels by US\$15 million the sign of a well-managed company. Per-Se supports some 47,000 physicians and 2,000 healthcare organizations. www.per-se.com

\section{Did you know?}

The First Hand Foundation focuses on pediatric healthcare. The First Hand mission is "to directly impact the health status of a young life." The foundation is a non profit organization supported by the Cerner

Corporation, its associates, business partners and friends. The associates make up the largest portion of the foundation's funding. In return for each associate's contribution, Cerner matches each donation dollar for dollar. The remaining funds are raised through individual gifts, annual fundraising events, memorial and honorarium programs and gifts of stock. First Hand assists individual children who have clinically relevant, healthrelated needs and no financial net to cover these expenses. For more information visit the website at www.firsthandfoundation.org. 


\section{The industry according to Microsoft}

Canadian IT companies that provide sales and services in support of Microsoft software products and services make a substantial contribution to the Canadian economy, according to an IDC Canada Consulting study. Commissioned by Microsoft Canada Co., the research reveals that more than 73,000 Canadians are employed by those companies, and contribute more than $\$ 5.5$ billion annually in product and services expenditures and salaries.

Microsoft notes that large multinationals might first come to mind when people think IT, but this study shows that the real impact comes from the tens of thousands of Canadian companies who work with them.

The IDC study found that despite recent economic difficulties in the technology sector, this IT sales and service "ecosystem":

- employs nearly 73,000 Canadians;

- typically pays salaries $38 \%$ higher than the national average; and

- accounts for $\$ 1.9$ billion in yearly product and services expenditures and $\$ 3.6$ billion in salary expenditures.

The importance of this contribution is underscored by recent studies which show Canada leading the U.S. in the recovery of high tech. Research studies by the American Electronics Association and Industry Canada reveal that while $10 \%$ of all tech jobs in the U.S. have disappeared since 2001, Canada's tech industry is growing faster than its GDP and is approaching the levels of the "tech boom" in 2000.

Microsoft's business is based on an indirect business model. It works with thousands of companies, such as independent software vendors who develop and market new products on the Microsoft platform, system integrators and value-added resellers who help companies implement and service Microsoft solutions and distributors as well as market Microsoft products for resale. The IDC study measured only the contributions of IT sales and service companies working with Microsoft and does not include the impact of other strategic alliances such as vendors and telecommunications companies.

Other IDC findings include:

- The Canadian software and IT channel as a whole accounts for $\$ 16.65$ billion in product and services expenditures.

- The channel as a whole employs 209,000 people.

- The Canadian software channel - a portion of the overall channel - accounts for $\$ 8.7$ billion in yearly product and services expenditures.

When business IT departments are included - private and public sector departments who procure, maintain, support or train others to use Microsoft products - Microsoftrelated employment increases to more than 240,000 . The staff of Canadian business IT departments also accounts for an additional $\$ 11$ billion in annual salary expenditures.

Soon we'll all reach out and touch $3 \mathrm{M}$. Those wonderful screens that allow users to touch an item within the display are now part of $3 \mathrm{M}$ technology and have just been introduced to Canada. Look for it. The company is a strong supporter of the CQI network, proving once again that quality and success can operate inseparably over the long haul.

McKesson Healthcare for at-risk youth is the primary focus of McKesson's charitable giving. With some $\$ 4$ million in annual grants, the McKesson Foundation would like to see that no child goes without needed medicine or treatment.

\section{Aramark}

For the second year in a row, Aramark has been named the No. 1 company in "Diversified Outsourcing Services" in Fortune magazine's new ranking of America's Most Admired Companies. Even more impressive, Aramark has moved from No. 48 to No. 10 in the overall score among the 580 companies included in the survey. ( Fortune's "Top Ten" in the magazine is based on number of votes, not overall score.) These results come on the heels of Aramark being named in the January issue of Business Week magazine as one of the Top 25 managed companies of 2002.

More ... Aramark has been awarded the contract to provide food service for the $\mathbf{2 0 0 4}$ Summer Olympic Games in Athens, Greece, by the Organizing Committee for the Olympic Games Athens 2004 (OCOG). The decision marks the 13th time Aramark has been selected to serve at the Olympic Games. 


\section{Transitions}

Johnson \& Johnson Medical Products and

HayGroup have indicated their support for the work of the Dorothy Wylie Institute. J\&J has a strong tradition of supporting nursing leadership development. Both organizations will be able to provide counsel and resources as the institute develops its programs.

South Huron Hospital's new CEO is John Sutherland.

Malcolm Moffat has been selected as the new President and Chief Executive Officer of Toronto's St. John's Rehabilitation Hospital, effective March 24, 2003. Mr. Moffat was Vice-President and Chief Planning Officer of St. Michael's Hospital.

\section{www.stjohnsrehab.com/appointment.html}

Canadian Blood Services announced the appointment of Dr. Verna M. Skanes of St. John's, Newfoundland, as interim Chair of the Board of Directors. She replaces Gary Chatfield of Mississauga, Ontario, who recently stepped down for personal reasons. www.bloodservices.ca

Dr. Robert S. Sheldon has been appointed to the Canadian Institutes of Health Research (CIHR) Governing Council. Dr. Sheldon is a distinguished researcher and physician. Over his career he has specialized in cardiology and arrhythmia disturbances. Dr. Sheldon has an active practice at the Foothills Hospital in Alberta, and he operates a basic and clinical research laboratory dedicated to understanding the causes and treatment of fainting. His lab also studies second-to-second regulation of heartbeats and blood pressure.

Ed Kilroy, IBM Canada President, has announced the appointment of Christine Alford as Canadian Leader and Partner, IBM Business Consulting Services, IBM Canada Ltd. Ms. Alford is responsible for leading the Canadian team of IBM consultants that is redefining business consulting in Canada.

\section{Ontario's new Provincial Chief Nursing Officer is}

Sue Mathews, who was most recently chief of nursing and professional practice at Southlake Regional Health Centre in Newmarket. As chief nursing officer, Mathews will advise the Ontario government on health and relevant public policy from a nursing perspective, foster collaboration between government and nursing stakeholders, and support the implementation and monitoring of the Nursing Task Force recommendations. In 1999, Ontario became the first jurisdiction in Canada to appoint a chief nursing officer.

Kimberley Elliott of Agfa Canada is the new Branding and Communications Manager for Agfa North America. Her focus: enterprise solutions.

Mr. André Marcheterre, President, Merck Frosst Canada, is very pleased to announce that Robert Davies has been appointed to the position of VicePresident, Health Education Services. In this new position Mr. Davies has responsibility for the planning, development and implementation of health education strategies designed to address the educational needs of healthcare providers. Mr. Davies will also retain responsibility for implementing market development strategies.

Sharp HealthCare, the largest healthcare provider in San Diego, California, has saved almost $\$ 18$ million since 1996 by using the One-Staff ${ }^{\circledR}$ enterprise-wide staff and productivity management solution from PerSe Technologies. The savings come from reducing overtime expenses and the use of costly staffing agencies to fill staff openings. Per-Se is a leading provider of integrated business management outsourcing services, application software and Internet-enabled connectivity for the healthcare industry.

www.per-se.com

"I just got this electronic Table of Contents for CJNL in my email today - that's great!" -St. Joseph's Healthcare, London, ON

Subscribe to e-journal. Enterprise-wide subscriptions. No log-in and no password required. Contact Susan Hale: shale@longwoods.com 